\title{
Chemical Dorsal Rhizotomy in Lung Cancer Pain
}

\author{
AHMED F. AHMED, M.Sc.; RAAFAT R. MAHFOUZ, M.D.; EMAD GERGES SALEH, M.D.; \\ SOMAYA A. EL SHEIKH, M.D. and MOHGA A. SAMY, M.D.
}

The Department of Anesthesia and Pain Relief, National Cancer Institute, Cairo University, Cairo, Egypt

\begin{abstract}
Background: Lung cancer is one of most common malignancies worldwide. Pain is one of the most prevalent symptoms in patients diagnosed with lung cancer. Many therapeutic modalities proposed to provide pain relief in those patients.

Aim of Study: The aim of this study was to assess the safety and effectiveness chemical dorsal rhizotomy (phenol) in treatment of chronic malignant thoracic pain.

Patients and Methods: This prospective interventional study included 30 patients with lung cancer pain. The patients received chemical phenol in dorsal rhizotomy corresponding to related pain dermatome at National Cancer Institute during the period from 1 st of January 2015 to end of December 2018.

Results: Visual analog scale, quality-of-life and quality of sleep scores were improved significantat Day 1, 1 week, $1 \mathrm{~m}$ and $3 \mathrm{~m}$ as compared to pre block. As regards complication, one case had dorsal back pain, and three cases had numbness.

Conclusions: Chemical rhizotomyleads to pain relief on short and long term but has concerns in safety profile.
\end{abstract}

Key Words: Chemical rhizotomy - Lung cancer-Chronic pain.

\section{Introduction}

LUNG cancer is the most common cancer in the world with 1.61 million new case diagnosed every year [1]. Pain is the most common symptom in cancer patients in general and in lung cancer specifically. The majority of patients with lung cancer have an advanced stage of the disease at clinical presentation. Symptoms may result from local effects of tumor, from regional or distant spread, or from distant effects not related to metastases (paraneoplastic syndromes) [2].

Patients with lung cancer experience more distressing symptoms than patients with other types of cancers [3]. Symptoms such as pain may be associated with worsening of other symptoms

Correspondence to: Dr. Ahmed F. Ahmed, E-Mail:drfahmof@gmail.com including respiratory distress, depression and fatigue [4] and may affect quality of life [5]

Pain resulting from lung cancer can be classified by two methods: Either by the type of pain or according to the origin of the pain. The location or origin of the pain may determine the type of pain experienced. Pain can also be affected by the histological type and biological behavior of the lung cancer present. Pain in patients with lung cancer can be differentiated according to its origin, namely intra-thoracic or extra thoracic, the latter of which may be the consequence of cancer complications.In the management of chronic cancer pain, the ability to ablate or modulate sensory nerve fibers to cause analgesia has intrigued physicians for many years. Chronic cancer pain is commonly controlled with pharmacologic agents alone. Even multimodal therapy-combining physical or occupational therapy, psychological interventions, and interventional procedures-may be suboptimal in providing adequate analgesia [6]

Chemical neurolytic agent used in dorsal rhizotomy. Phenol is a chemical composite, highly soluble in organic solvents as alcohol and glycerol. When mixed with glycerol, it causes localized destruction, while when mixed with water causes a bigger area of nerve destruction. Mode of actionis loss of cellular fatty elements, separation of myelin sheath from the axon, axonal edema and protein precipitation [7]

The aim of this study was to assess the safety and effectiveness chemical dorsal rhizotomy (phenol) in treatment of chronic malignant thoracic pain.

\section{Patients and Methods}

This prospective interventional study included 30 patients with lung cancer pain selected from 
pain clinic at National cancer institute after approval from Ethical Committee and obtaining informed written consent during the period from ${ }^{\text {st }}$ of January 2015 to end of December 2018.

The patients received chemical phenol in dorsal rhizotomy corresponding to related pain dermatome.

The inclusion criteria were patients with chest pain (anterior, posterior) due to lung cancer, failed medical treatment, presence of complication e.g: vomiting, constipation, narcosis of opioids, age between $(18 y-65 y)$, good general condition and ability to lie prone, and ability to lie lateral on the painful side for at least 1 hour.

The exclusion criteria were patients with coagulation defects neurological defect, epidural metastases, vertebral collapse, osteolytic lesions at entry site of the needle, local infection, psychiatric illnesses, sepsis, poor general condition and severe respiratory distress.

Patients were subjected to assessment before procedure: Complete personal history, psychological examination, physical examination, pain assessment (VAS, sleep rhythm, physical activity), laboratory: CBC. Coagulation profile (PC\%-PTINR) andradiological: plain chest X-ray and MRI spine.

\section{Chemical neurolytic of DRG technique:}

Under aseptic precaution, the patient was placed in the lateral position on a flat operating table with the painful side underneath. The target nerve is identified using $\mathrm{C}$-arm fluoroscopy.

A local anesthetic is infiltrated at the skin. Then, 20G-3.5 inches Quincke spinal needle is advanced until reached its position which is again confirmed via $\mathrm{C}$-arm fluoroscopy \& free CSF flow. The hyperbaric phenol $6 \%$ in glycerin was injected intrathecally $(0.1-0.2 \mathrm{ml}$ segment or total of $0.5 \mathrm{ml}$ in females \& $0.7 \mathrm{ml}$ in males). The patient was tilted $45^{\circ}$ backards to deposit the injected phenol in glycerin (hyperbaric technique) on the lower most dorsal sensory rootlets. This posture was maintained for 45 minutes thereafter. At the end of procedure, patient is transported to Post Anesthetic Care Unit (PACU) for 1-hour post block, Patient was monitored (pulse, blood pressure and oxygen saturation) to ensure hemodynamic stability and exclude neurological insult or pneumothorax, then discharged to ward or home.

Pain assessment: The patient had been assessed: Pre procedure. Immediately after procedure, 1 week,
4 weeks, 12 weeks, for pain assessment using: Visual analogue scale VAS scale: Patients were asked to assess pain intensity using $100 \mathrm{~mm}$ visual analog scale (VAS). In which '0' represents no pain, "100" mean maximum pain imagined. Sleep rhythm (using sleep scale score): 0 normal rhythm, 1 interrupted, 2 inefficient, 3 disturbed, 4 hard with hypnosis, 5 no sleep. Physical activity (using Physical activity scale score): 0 In work, 1 Sick leave, 2 Home activity, 3 Limited, 4 Isolated, 5 Bedridden.Consumption of analgesic drugs: Including opioids (Oxycontin $\left.{ }^{\circledR}\right)$, and adjuvants (Lyrica ${ }^{\circledR}$ ). Complications and side effects of phenol: Deafferentation, neuritis, motor impairment, back pain, infection and sphinctericsequalae.

\section{Statistical analysis:}

Data were analyzed using SPPS version 16 . Numerical data will be expressed as mean and standard deviation or median and rang as appropriate. For quantitative data comparison were done using repeated measures ANOVA. A $p$-value of $\leq 0.05$ were considered significant.

\section{Results}

Mean age was $50.4( \pm 9.4), 26.7 \%$ were females and $73.3 \%$ were males. $46.7 \%$ had neuropathic burning pain, $3.3 \%$ had neuropathic lancinating pain, $16.7 \%$ had neuropathic lancinating burning pain, $33.3 \%$ had nociceptive dull ache pain, and $43.3 \%$ had pain on the left side and $56.7 \%$ had pain on the right side. $26.7 \%$ of pain was due to bronchogenic origin, $50.0 \%$ was duemesothelioma, $6.7 \%$ was due post thoracotomy Adenocarcinoma, $6.7 \%$ was due post thoracotomy mesothelioma and $10.0 \%$ was due small cell carcinoma. Meannumber of affected dermatomes was 3.50 ( \pm 0.63$)$. Table (1).

Mean pre block vas score was $8.07( \pm 0.91)$, mean Day 1 VAS score was $2.27( \pm 0.58)$, mean 1 week VAS score was $2.00( \pm 0.45)$ mean $1 \mathrm{~m}$ VAS score was $2.00( \pm 0.37)$ and mean $3 \mathrm{~m}$ VAS score was $2.53( \pm 0.97)$. There was significant improvementin Day 1,1 week, $1 \mathrm{~m}$ and $3 \mathrm{~m}$ regarding to VAS score as compared to pre-block. Table (2).

Mean pre block Quality of life score was 3.87 $( \pm 0.68)$, mean Day 1 Quality of life score was 1.93 $( \pm 0.45)$, mean 1 week Quality of life score was $1.80( \pm 0.41)$, mean $1 \mathrm{~m}$ Quality of life score was $1.73( \pm 0.45)$ and mean $3 \mathrm{~m}$ Quality of life score was $1.83( \pm 0.53)$. There was significant improvementin Day 1,1 week, $1 \mathrm{~m}$ and $3 \mathrm{~m}$ regarding to Quality of life as compared to pre-block. Table (3). 
Mean pre block Quality of sleep score was 3.73 $( \pm 0.83)$, mean Day 1 Quality of sleep score was $1.77( \pm 0.57)$, mean 1 week Quality of sleep score was $1.63( \pm 0.49)$, mean $1 \mathrm{~m}$ Quality of sleep score was $1.53( \pm 0.51)$ and mean $3 \mathrm{~m}$ Quality of sleep score was $1.80( \pm 0.66)$. There was significant improvementin Day 1,1 week, $1 \mathrm{~m}$ and $3 \mathrm{~m}$ regarding to Quality of sleep as compared to pre-block. Table (4).

Table (1): Patients demographic data, type and site of pain and cause and number of affected dermatomes.

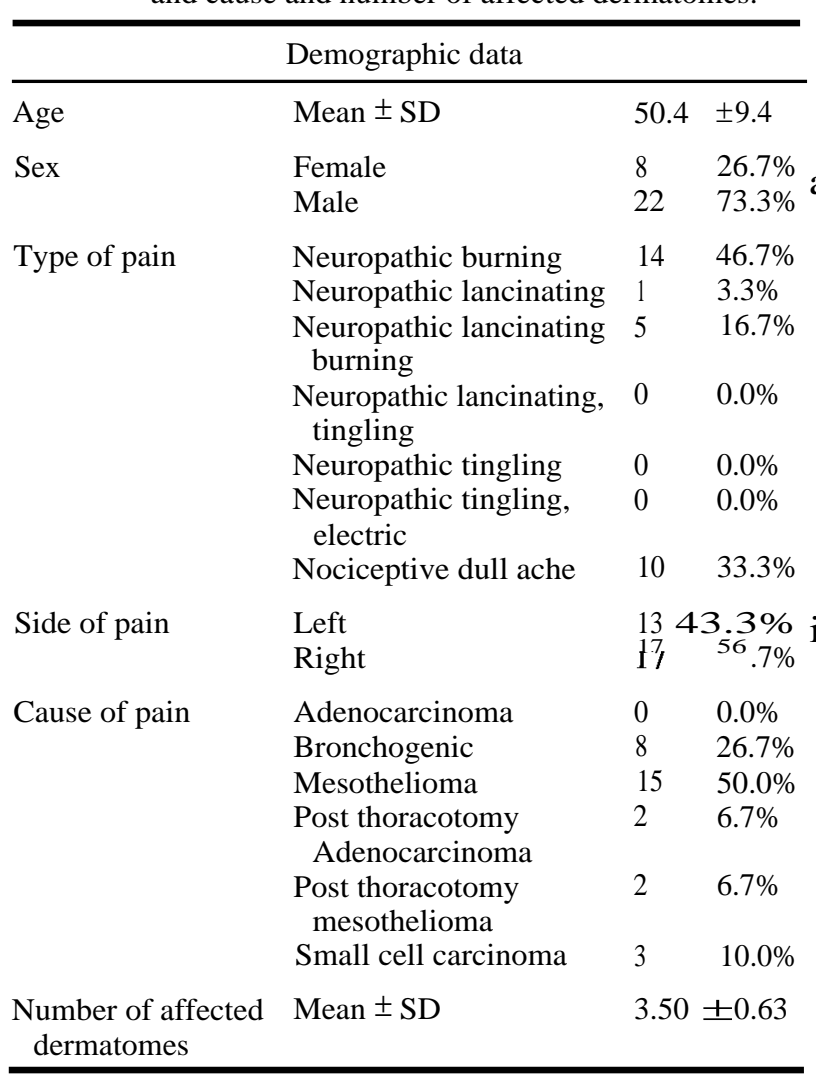

Table (2): Comparison of the VAS score over time in patients.

\begin{tabular}{lcc}
\hline \multirow{2}{*}{ VAS } & Chemical dorsal rhizotomy & \\
\cline { 2 - 2 } & Mean \pm SD & \\
\hline Pre-Block & $8.07 \pm 0.91$ & \\
Day 1 & $2.27 \pm 0.58$ & $<0.001$ \\
1 Week & $2.00 \pm 0.45$ & $<0.001$ \\
1 Month & $2.00 \pm 0.37$ & $<0.001$ \\
3 Months & $2.53 \pm 0.97$ & $<0.001$ \\
\hline
\end{tabular}

Table (3): Serial Follow-up for quality-of-life score in patients.

\begin{tabular}{lcc}
\hline \multirow{2}{*}{ Quality of life } & Chemical dorsal rhizotomy & \\
\cline { 2 - 2 } & Mean \pm SD & \\
\hline Pre-Block & $3.87 \pm 0.68$ & \\
Day 1 & $1.93 \pm 0.45$ & $<0.001$ \\
1 Week & $1.80 \pm 0.41$ & $<0.001$ \\
1 Month & $1.73 \pm 0.45$ & $<0.001$ \\
3 Months & $1.83 \pm 0.53$ & $<0.001$ \\
\hline
\end{tabular}

Table (4): Serial Follow-up for quality of sleep score in patients.

\begin{tabular}{lcc}
\hline Quality of sleep & Chemical dorsal rhizotomy & \\
\cline { 2 - 2 } & Mean \pm SD & \\
\hline Pre-Block & $3.73 \pm 0.83$ & \\
Day 1 & $1.77 \pm 0.57$ & $<0.001$ \\
1 Week & $1.63 \pm 0.49$ & $<0.001$ \\
1 Month & $1.53 \pm 0.51$ & $<0.001$ \\
3 Months & $1.80 \pm 0.66$ & $<0.001$ \\
\hline
\end{tabular}

\section{Discussion}

Dorsal root ganglion (DRG) is a ganglion that is located in dorsal root of spinal cord. It accepts and regulates different type of sensation including pain. Different therapeutic modalities applied to DRG have marked effects on the intractable pain caused by cancer [8]

We used DRG as a target for intervention due to relatively constant site of the ganglion unlike paravertebral and intercostal nerve which may be displaced by tumor infiltration besides it may induce deafferentation pain and miss a proximal pain generator [9]. Targeting DRG showed a promising result in many published trials [10]. Targeting DRG has many advantages including less risk of inadvertent dural puncture, direct anterior epidural access and more therapeutic value in treating chronic radicular pain [11]

Patients in our study showed great reduction on VAS score on the first day. But higher VAS score was reported on day 1 and week after intervention. After one and three months, patients scored similar VAS score with no significant difference.

Chemical rhizotomy on DRG is another reported method for pain relief. Which involves injecting a neurolytic material such as alcohol or phenol [12].

Chemical rhizotomy may provide analgesia for patients with lung cancer. For lung cancer pain patients, the options include epidural new catheter technique for thoracic subarachnoid neurolysis in advanced lung cancer patients [13]. It can be performed at any level up to the mid-cervical regions, where the spread of neurolytic agent to the medullary center carries an unacceptable risk of cardio respiratory collapse [14]

Though many studies reported side effect for this procedure i.e. uncontrolled intraspinal spread and high risk for neurological deficits which may limit its use in clinical practice which limit its use in cancer patients [14] 
In a case of 58-year-old woman with advanced non-small cell lung cancer, after reaching maximum tolerated doses of oral analgesics, patient elected for intercostal nerve blockade and neurolysis with phenol. Prognostic nerve blockade was performed using liposomal bupivacaine administered via intercostal approach that provided an excellent prognostic blockade, which lasted for approximately 96 hours. This case suggests that liposomal bupivacaine may be a valuable adjunctive agent for prognostic blockade prior to neurolysis for cancer pain [15].

A case series describes 11 cancer patients with chest wall pain (six patients subsequently received chemical neurolysis with phenol). Most of patients experienced pain relief. However, contrast dye spread liberally from the intercostal space into other anatomic spaces, even though very small volumes of injectate (less than $5 \mathrm{~mL}$ ) were used [16].

A randomized clinical trial compared injecting local anesthetic and alcohol at the same point versus two-point method, in which the local anesthetic and alcohol were given at different sites. Injecting Local anesthetic in upstream of the point where alcohol was administered, was a feasible and safe method to relieve pain during the operation, and improved the satisfaction of the patients and curative effect [15].

Regarding complications, our result showed numbness and mild dorsal back pain.

A case report for 42-year-old female patient with lung cancer developed paraplegia after receiving intercostal nerve neurolysis and interlaminar epidural steroid injections. MRI results revealed extensive swelling of the spinal cord between the T4 spinal cord and conusmedullaris. Although steroid therapy was administered, the paraplegia did not improve [17]

Another case report points to the risks involved with phenol neurolysis close to the spine. A case of a 66-year-old female developed paraplegia following intercostal neurolysis with phenol. One hour after the procedure, the patient developed bilateral lower extremity weakness with difficulty moving. A physical examination showed the absence of sensation to pinpricks and vibration from T10 to S5 and an absence of anal sphincter tone and sensation. The authors hypothesized paraplegia could be from phenol diffusing along either the spinal nerves or the paravertebral venous plexus into the subarachnoid space [18].
A 55-year-old man with severe scoliosis and chest deformity was scheduled for an intercostal neurolysis for pain relief with $7.5 \%$ aqueous phenol solution. Within a minute after the injection, the patient felt a warm sensation in his right leg, followed by loss of leg motor and sensory function on both sides. The most likely explanation is a diffusion of the phenol through the intervertebral foraminae reaching the spinal space and therefore damaging the motor and sensory roots [19]. In the current work $6 \%$ phenol in glycerol was used to limit phenol spread only to dorsal sensory roots.

A 53-year-old women acute onset of lower extremity paresis beginning shortly after right intercostal nerve injections of $2 \mathrm{~mL}$ of preservativefree phenol at the T7, 8, 9 levels. One month after presentation, despite radiographic improvement, the patient showed some clinical improvement, but remained walker dependent and with neurogenic bowel and bladder [20].

Due to effective of the intervention, other complications were not reported in our study including; Infection (by strict sterilization), Pneumothorax (by respecting the rule of keeping site of skin entrance within the $4 \mathrm{~cm}$ from middle line for all thoracic interventional spinal procedures), deafferentation pain (due to sensory overlap phenomenon of thoracic dermatomes) [21]

This study has several limitations, small sample size and follow-up period was only for three months. We could not asses the relation between origin of chest pain (weather from bone metastasis, pleural origin ...etc.) and efficacy of the intervention.

Evidence showed paravertebral block had advantage over epidural analgesia regarding hemodynamic stability. A randomized trial on 32 patients underwent open lung surgery. Results showed paravertebral block had greater hemodynamic stability than epidural analgesia. Moreover, paravertebral block also required smaller volume of colloids and vasopressors to maintain the target oxygen delivery index. However, both had the same efficacy in providing proper analgesia [22].

A systematic review on 698 participants undergoing thoracotomy. They concluded that paravertebral blockade reduced the risks of developing minor complications compared to thoracic epidural blockade. Paravertebral blockade was as effective as thoracic epidural blockade in controlling acute pain. There was a lack of evidence in other outcomes. There was no difference in 30-day mortality, major complications, or length of hospital stay. 
There was insufficient data on chronic pain and costs. However, results from this review should be interpreted with caution due to the heterogeneity of the included studies and the lack of reliable evidence [23]

A meta-analysis on 1120 patients concluded that continuous paravertebral block has equivalent analgesic effects to epidural analgesia, wound infiltration and standard care, but is associated with a lower incidence of nausea and vomiting, hypotension and urinary retention than epidural analgesia [24].

It is reported that paravertebral block associated with decreased incidence of chronic pain score, fewer symptoms and signs of chronic pain, and also experience better physical and mental healthrelated quality of life [25]

Ultrasound-guided paravertebral block provides fewer incidences of complications; a study compared ultrasound-guided paravertebral block to thoracic epidural block in patient underwent lung surgery. No difference in the frequency of taking supplemental analgesics in both groups. Hypotension occurred significantly more frequently in thoracic epidural block group; on the other hand, the incidences of postoperative nausea and vomiting and pruritus, as well as overall satisfaction score, were similar in both groups [26]

A recent clinical trial compared intercostal nerve block and epidural analgesia-in patients scheduled to undergo thoracoscopic lobectomy and lymphadenectomy. Postoperative pain during postoperative days 0-7 was not significantly different between the groups. Concluding that intercostal nerve block followed by high-dose oral celecoxib seems to be an alternative for epidural Analgesia patients undergoing thoracoscopic lobectomy for lung cancer. Although limited sample size compromised the ability to draw definitive conclusions [27].

\section{Conclusions:}

Chemical rhizotomyleads to pain relief on short and long term but has concerns in safety profile.

Financial support and sponsorship:Nil.

Conflict of Interest: Nil.

\section{References}

1- SHAKOOH S. and BHOSLE P.: Intrathecal nalbuphine: An effective adjuvant for post operative analgesia. Contract No.: 14.09, 2014.
2- CARACENI A. and PORTENOY R.K.: An international survey of cancer pain characteristics and syndromes. Pain, 82: 263-74, 1999

3- COOLEY M.E.: Symptoms in adults with lung cancer: A systematic research review. J. Pain Symptom Manage, 19: 137-53, 2000.

4- LAIRD B.J., SCOTT A.C., COLVIN L.A., MCKEON AL., MURRAY G.D., FEARON K.C., et al.: Pain, depression, and fatigue as a symptom cluster in advanced cancer. J. Pain Symptom Manage, 42: 1-11, 2011

5- LAIRD B.J., WALLEY J., MURRAY G.D., CLAUSEN E., COLVIN L.A. and FALLON M.T.: Characterization of cancer-induced bone pain: An exploratory study. Supportive Care in Cancer, 19: 1393-401, 2011.

6- EWERT T., LIMM H., WESSELS T, RACKWITZ B., VON GARNIER K., FREUMUTH R., et al.: The comparative effectiveness of a multimodal program versus exercise alone for the secondary prevention of chronic low back pain and disability. PM\&R, 1: 798-808, 2009.

7- WILKENING M., FARCY J., WALCZAK C., ROCHER P. and GONIN M.: Chemical neurolysis in the treatment of cancer pain. Neurochirurgie, 22: 735-48, 1976.

8- YG J., LH X. and ZHANG H.J.I.J.P.R.: The role of dorsal root ganglia in pain mechanism and treatment. Int. J. Pharma Res., 35: 18-22, 2008.

9- GULATI A., SHAH R., PUTTANNIAH V., HUNG J.C. and MALHOTRA V.J.P.M.: A retrospective review and treatment paradigm of interventional therapies for patients suffering from intractable thoracic chest wall pain in the oncologic population. Pain Med., 16: 802-10, 2015.

10- SON K.M., LEE S.M., LEE G.W., AHN M.H. and SON J.H.JP.P.: The impact of lumbosacral transitional vertebrae on therapeutic outcomes of transforaminal epidural injection in patients with lumbar disc herniation. Pain Pract., 16: 688-95, 2016.

11- POUNTOS I., PANTELI M., WALTERS G., BUSH D and GIANNOUDIS PVJDiR.: Safety of epidural corticosteroid injections. Drugs R\&D., 16: 19-34, 2016.

12- CANDIDO K. and STEVENS R.A.J.B.P.: Anaesthesiology RC. Intrathecal neurolytic blocks for the relief of cancer pain. Best Pract Res. Clin. Anaesthesiol., 17: 407-28, 2003.

13- CANDIDO K. and STEVENS R.A.: Intrathecal neurolytic blocks for the relief of cancer pain. Best Pract Res. Clin. Anaesthesiol., 17: 407-28, 2003.

14- PATT R. and REDDY SJAotAoM: Singapore. Spinal neurolysis for cancer pain: Indications and recent results. Ann. Acad. Med. Singap, 23: 216-20, 1994.

15- YIN C. and MATCHETT GJJoP: Pharmacotherapy P.C. Intercostal administration of liposomal bupivacaine as a prognostic nerve block prior to phenol neurolysis for intractable chest wall pain. J. Pain Palliat Care Pharmacother., 28: 33-6, 2014.

16- MATCHETT GJJoP: Pharmacotherapy PC. Intercostal nerve block and neurolysis for intractable cancer pain. J. Pain Palliat Care Pharmacother., 30: 114-7, 2016.

17. KIM B.H., NO M.Y., HAN S.J., PARK C.H. and KIM JHJTKJoP.: Paraplegia following intercostal nerve neurolysis with alcohol and thoracic epidural injection in lung cancer patient. Korean J. Pain, 28: 148, 2015. 
18- GOLLAPALLI L. and MUPPURI RJJoPR.: Paraplegia after intercostal neurolysis with phenol. J. Pain Res., 7: $665,2014$.

19- KOWALEWSKI R., SCHURCH B., HODLER J. and BORGEAT AJAopm: rehabilitation. Persistent paraplegia after an aqueous $7.5 \%$ phenol solution to the anterior motor root for intercostal neurolysis: A case report. Arch. Phys. Med. Rehabil., 83: 283-5, 2002.

20- KISSOON N.R., GRAFF-RADFORD J., WATSON J.C. and, LAUGHLIN RSJPP.: Spinal cord injury from fluoroscopically guided intercostal blocks with phenol. Pain Physician, 17: E219-24, 2014.

21- TEIXEIRA A., GRANDINSON M. and SLUIJTER MEJPP.: Pulsed radiofrequency for radicular pain due to a herniated intervertebral disc-an initial report. Pain Pract., 5: $111-5,2005$.

22- PINTARIC T.S., POTOCNIK I., HADZIC A., STUPNIK T., PINTARIC M. and NOVAK JANKOVIC V.: Comparison of continuous thoracic epidural with paravertebral block on perioperative analgesia and hemodynamic stability in patients having open lung surgery. Reg. Anesth. Pain Med., 36: 256-60, 2011.

23- YEUNG J.H., GATES S., NAIDU B.V., WILSON M.J. and SMITH FGJCDoSR.: Paravertebral block versus thoracic epidural for patients undergoing thoracotomy. Cochrane Database Syst Rev., 2016.

24- SCARFE A.J., SCHUHMANN-HINGEL S., DUNCAN J.K., MA N., ATUKORALE Y.N. and CAMERON ALJEjoc-ts.: Continuous paravertebral block for postcardiothoracic surgery analgesia: A systematic review and meta-analysis. Eur. J. Cardio-Thorac. Surg., 50: 10108, 2016.

25- KARMAKAR M.K., SAMY W., LI J.W., LEE A., CHAN W.C., CHEN P.P., et al.: Thoracic paravertebral block and its effects on chronic pain and health-related quality of life after modified radical mastectomy. Reg. Anesth. Pain Med., 39: 289-98, 2014.

26- OKAJIMA H., TANAKA O., USHIO M, HIGUCHI Y. NAGAI Y., IIJIMA K., et al.: Ultrasound-guided continuous thoracic paravertebral block provides comparable analgesia and fewer episodes of hypotension than continuous epidural block after lung surgery. Anaesthesiol. Intensive Ther., 29: 373-8, 2015.

27- UEDA K., HAYASHI M., MURAKAMI J., TANAKA T., UTADA K., HAMANO K.J.G.T., et al.: Intercostal block vs. epidural analgesia in thoracoscopic lung cancer surgery: A randomized trial. Gen Thorac. Cardiovasc. Surg., 68: 254-60, 2020.

\section{علاج الألم الناتج عن سرطان الرئة باستخدام حقن الجذور العصبية العنية بالفينول}

$$
\begin{aligned}
& \text { يعد سرطان الرئة من أكثر الأمراض الخبيثة شيوعاً فى جميع أنحاء العالم. يعد الألم من أكثر الأعراض انتشاراً لدى مرضى سرطان الرئة. }
\end{aligned}
$$

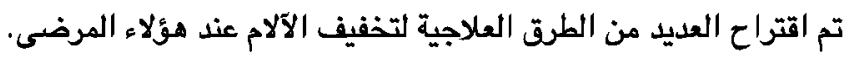

$$
\begin{aligned}
& \text { الهدف من الرسالة: هدفت هذه الدراسة إلى تقييم سلامة و فعالية بضع الجذور الظهرية كيميائياً بالفينول فى علاج آلام الصدر السرطانية } \\
& \text { المزمنة. }
\end{aligned}
$$

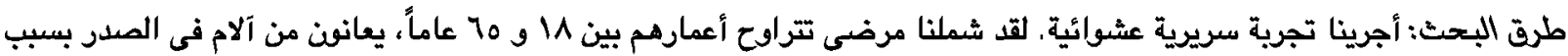

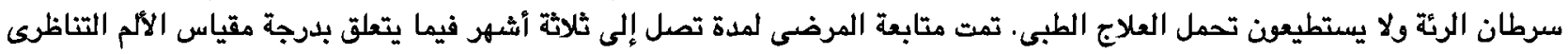

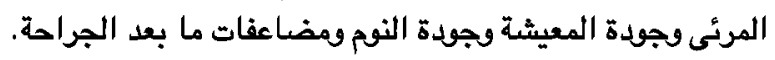

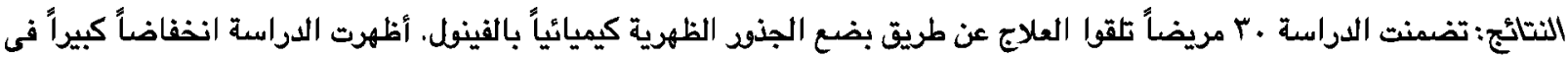

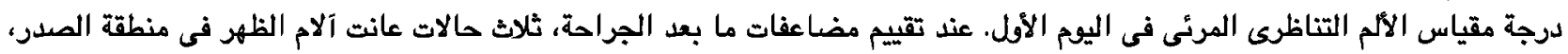

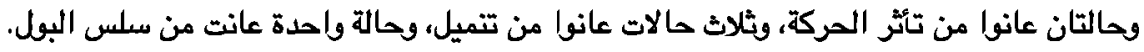

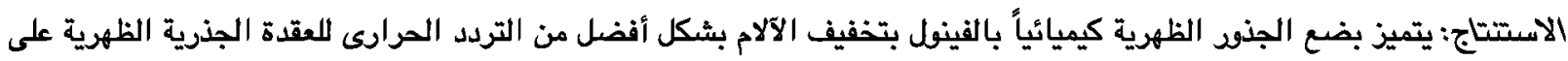

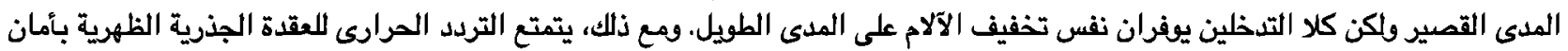
أفضل مقارنة بيضع الجذو الظهرية كيميائياً بالفينول. 